\title{
Globalization and Rise of Terrorism
}

\author{
Genc Mekaj ${ }^{1}$ \\ ${ }^{1}$ College ILIRIA \\ 75 Gazmend Zajmi Street, Prishtinë, 10060, Republika e Kosovës
}

DOI: $10.22178 /$ pos.62-11

JEL Classification: H54

Received 19.08.2020

Accepted 25.09.2020

Published online 30.09.2020

Corresponding Author:

gencmeka@hotmail.com

(c) 2020 The Author. This article

is licensed under a Creative Commons

Attribution 4.0 License @ (1)

\begin{abstract}
Globalization today has engulfed the entire world, extending and taking place on the most important national and international agendas. The process of globalization includes great developments between countries around the world, technological, economic, cultural, scientific, etc, but is also considered by many countries as a threat to their country. On the one hand, globalization between different countries brings great relief and profits in many areas. On the other hand, globalization brings with it risks that have long-term and profound consequences. With the development of globalization, the challenges for the world have increased making them more difficult to face. One of the great challenges that have evolved through globalization is the rise of terrorism. Through this paper, we have attempted to present the rise and advancement of terrorism through globalization. In a related way, we will present the impact of globalization which was exploited by terrorism for illegal purposes as well as to bring danger to the world. In this paper, through descriptive, analytical, and comparative methods, we have tried to present how globalization has led to the rise and spread of terrorism globally. In conclusion, we can conclude that globalization has facilitated the development of terrorism, making the impact of terrorism and their activities much easier to spread across the globe.
\end{abstract}

Keywords: terrorism; impact; globalization; challenges.

\section{INTRODUCTION}

Globalization during its expansion and development has brought with it many bad actors for countries and society in general, one of these actors is terrorism. Globalization has also raised terrorism and its threat globally. With the development of globalization, the challenges for the world have increased making it more difficult to face them. One of the great challenges that have evolved through globalization is the rise of terrorism. It can be said that the greater and more developed the effect of globalization, the more developed and higher is the level of terrorism.

Major developments in many fields such as: economic, technological, scientific, development of high technology, development in the military field, advancement in sophisticated equipment and systems, as well as many other developments, all thanks to globalization reach almost every corner of the globe. All these achievements have their impact even greater thanks to globalization, but which pose a risk in many respects, especially in terms of the rise of terrorism.
It is precisely these above points that our study aims to address, in an interrelated way. Through the study of globalism, its extent, and the impact we can know and analyze how the rise of terrorism has taken place globally.

The impact of globalization today is a very sensitive issue for all countries in general which need to cooperate more collectively to advance them internally and internationally. But often these countries see globalization as unfavorable for their national interests.

Globalization has brought great challenges to all countries across the globe. With great developments and the opening of roads between states, globalization poses a great challenge to the security of all countries. These facilities of globalization have also brought facilities to terrorist groups and various terrorist organizations which operate easily across the globe and have deep access to various countries which pose a danger to all people. 
The main effects of globalization are the introduction of new and advanced technologies that are very advanced. Today globalization has made the world much more interconnected and interdependent in many respects. Thus, these referrals have made much easier the exchange of information between terrorist groups, as well as the advancement of their techniques, strategies, and goals.

It can rightly be said that globalism has made terrorism rise, raising it to the global level, as well as making every action and extension of it more dangerous.

\section{RESULTS}

\section{The impact of globalization}

Globalization today is spread all over the globe, its impact and expansion are increasing every day and more. The interconnectedness of developments in many areas through globalization has become easier, but at the same time has brought great risks from the development of bad, illegal phenomena.

Globalization has undoubtedly caught the imagination of many, judging by the enthusiasm with which the term is so frequently used by scholars, policymakers, the business community, mass media, and the general public. Intuitively, the term articulates how the contemporary world is becoming more interdependent, with events in one part of the world impacting elsewhere [9].

Definitions regarding globalization are numerous and varied. Also, the impact of globalization in many areas is great, which has made the interconnectedness and interdependence between different countries, with and without their will.

Globalization involves everything from the most diverse cultural dimensions and to the exchange of ideas, otherwise, globalization not only involves the economy but is versatile [3].

Due to globalization, there is comprehensive cooperation of many factors in the world including all disciplines and fields. As a result of the interconnectedness of globalization, the extension of many international actions occurs from the influences of the latter. So, it can be rightly said that globalization is a very deep and complex process. Also, globalism is a new ideological orientation that has a continuous global impact.
Globalization involves "expanding, deepening and accelerating international connectivity" [11]. Based on these effects, globalization has extended its impact around the world, increasing through international ties the dependence of the interests and goals of countries between them. On the one hand, many countries have consistently benefited from the impact of globalization. On the other hand, the expansion and acceleration of international ties carry in many cases hidden risks and maxims which are unpredictable. The dangers posed by the impact of globalization are often hidden within its positive sides.

Drastic developments in technology and communication have intensified the ever-increasing speed of globalization [6]. Today globalization has made the world a "global city or village" the interconnectedness that has made the world side by side, has made the globe look much smaller and looks like a flat field where everything lies within it. Technological developments, especially new technologies, have made the flow and impact of globalization easily conquer the world.

Advanced technologies, networking developments, and computerized advances, information, related information, articles, international exchanges electronically, and many other ways that have enabled modern technologies, constitute the flow and impact of globalization.

The effects of globalization cannot be just negative. In some cases, globalization can be considered as something good while in some other countries is seen as something bad. Countries that have become more open to the global system may be able to increase their economic sustainability, but those countries that are subject to the integration process or face the consequences of globalization may experience cramps or may have a consequence [8].

Many countries have benefited from the process of globalization and its impact because involvement in the process of globalization brings many benefits and good. But many great changes have taken place as a result of globalization, changes which in different cases and actions bring anxiety as a result of the changes brought about by the impact of globalization.

Economic interactions between different countries can cause anxiety due to social and cultural change [7]. So social levels within society and countries in general vary. As a result of these changes, social inequality arises and the process 
of imposed economic, social, and cultural changes begins. These changes are due to the impact of globalization which imposes adaptation through competition and innovations which are served to you every day by the impacts of globalization, intentionally or unintentionally.

Globalization often brings difficulties for many countries which have problems in accessing and effects on the latter. Zimmerman describes globalism as "exchanging ideas, goods, people" [13]. So, globalization involves a huge impact, with a wide range of developments and influences from many factors in many aspects.

Through the rapid and pervasive impacts of globalization on the above aspects, the challenges for the world at large have increased. By increasing economic interactions, development and exchange of ideas, interactions in many fields, as well as the development of fast and high technologies, before all these developments countries and society have been subjected to their will or without their will, where the main factor is the impact of globalization. All the above actions and developments cooperate interactively with each other, to create a world as globalized and interconnected as possible.

Thus, through the process of globalization, how they circulate and interconnect the world has brought great implications and facilitation for illegitimate purposes. The ways and developments brought about by the impact of globalization are often used for various purposes, other than those that are efficient, positive, and adequate.

Terrorism is one of the side effects which is inadvertently manifested by the impact of globalization, which continuously constitutes the greatest challenge that the latter has brought. This challenge has gripped all countries and states which find it difficult to adequately fight this all-round enemy.

The interconnectedness of the world through the extension of globalization, by terrorism, has facilitated its development and extension in a tactical as well as a coherent way to its goals. Also, the development of the economy, the opening of markets, the development of high technologies, the networking of technological interconnections, the possibility of facilitating communication between different countries, as well as between people around the globe has increased the possibility and affinity of terrorist groups that to extend, develop and achieve their evil and illegal intentions.
Due to globalization, the cooperation and interaction of many different actors around the world have increased. These interactions and collaborations of various actors that have been made possible by globalization, by terrorism have been seen and continuously used as a vacuum and opportunities to penetrate through them, to achieve their illegitimate goals.

While the impact of globalization has caused terrorism and various terrorist groups to continue to benefit, this has brought great instability and uncertainty to various areas around the world making even highly developed countries and high and advanced security to feel weak in the face of this hidden and unaddressed danger. Thus, globalization became an important cause for the rise and development of terrorism, especially at the global level.

\section{Globalization and the rise of terrorism}

Globalism has expanded its reach across the globe, which is often unaccepted by public opinion, society, and countries in general. Globalization affects all aspects depending on the positions and perspectives in which these aspects lie and are found. Globalization can be defined as a set of processes in many areas; economic, cultural, social, religious, political, etc. Anthony Giddens argues that: globalization can be associated with profound changes in the relationships (in time and space) of actuality [1]. Precisely the possibilities of changing globalization and adapting the actuality through the latter have made and influenced the rise and progress of terrorism.

Terrorism exploits all the benefits, grievances, and challenges that globalization brings, to achieve its points and interests. Terrorism from the challenges of globalization has risen and spread to a much greater and faster extent in different countries, states, and around the world.

It is already known that underdeveloped countries cannot be measured with large economies and developed countries. These two paradoxes cannot compete against each other. This leads precisely to the space between the rich and the poor, which can serve as the origin of anger and nervousness of those who do not have the opposite of what they have [10]. This dissatisfaction may adversely affect these people [4]. Globalization is responsible for economic and social inequality, in other words, is a cause for social polarization within the country [13]. So out of 
resentment, anger, and resentment, different people and groups can use terrorism as a way of expressing their resentment and nervousness.

Globalization also brings inequality and through a state that no longer can protect groups that are affected by the global economic challenges facing the world [13]. Large global inequalities affected by globalization can have internal impacts and effects in certain countries which pose internal challenges as a cause of globalization and the challenges that globalization brings. This inequality is largely exploited by terrorist groups who, taking advantage of the challenges and opportunities, try to more easily deport them into the creation of their illegal fields and networks. Thus, the spread and development of terrorism around the world today have occurred precisely because of globalization and its aid. Terrorism to a large extent is influenced and comes from external factors and it is precisely these mitigation mechanisms that globalization enables and facilitates.

Its technology and its rapid and large-scale advancement are also one of the key indicators that have facilitated the rise and spread of terrorism in the age of globalization.

Often, the internet has been identified as a useful tool to promote various terror-based ideas. Some software programs allow ease of use and this brings advantages and ideas for terrorist attacks. Since the internet is a fully anonymous forum, it provides users with its use for establishing communication networks [2]. Drastic developments in technology and communication have intensified the ever-increasing speed of globalization [6]. The advancement of new technologies as well as the rapid access of the globe to the adequate information, as well as the connection of the globe between different groups and individuals, has made advantages and premises for the realization of the goals of terrorist groups. All these are from globalization which has made the rise of terrorism in certain periods of development.

I can say that globalization helps terrorism because it has become an important tool of ideology and competition by providing easier access to new financial resources and providing weapons to terrorists [13]. Production, profession, and also the exchange of information within and also between terrorist teams have additionally been impacted by technical advancement, professional openness, and also international market adjustments [12].
Globalization has brought the possibility of facilitating communication with various means between people and countries. At this point, the possibility that terrorist groups may affect different people by making them part of their malicious organizations increased. Transport facilitation has also made these terrorist groups more likely to increase the number of their members. Globalization has also affected the spread of terrorism and the techniques used. Moreover, globalization has enabled these terrorist groups to attract members not only domestically but also from other countries [8].

Globalization is the most adequate area in which all the facilities for the development and rise of terrorism are found worldwide. With an emphasis on the field of information, ease of access as well as technological advancements has made globalization the cause of the rise of terrorism.

Terrorism has become more widespread with the use of social networks. The best example of this is the Islamic State in Syria and Iraq (ISIS), which has recently attempted to recruit soldiers from other countries in their ranks to incite terrorist attacks and make them a reality. Modern transport links have facilitated the journey, allowing the launch of terrorist attacks in foreign countries [8].

Terrorism in all possible ways and conditions has exploited globalism to raise and advance terrorism in certain countries, and around the world. When analyzing the periods in which globalization has taken off, we can see the progress of terrorism in those same periods.

The number of terrorist attacks around the world has risen steadily over the last 50 years or so. This is confirmed by the statistics which we will present below in the years 1970-2017. Well, globalization in the last 50 years has undergone greater developments, conquering the world, its extent, and its impact. It is by drawing parallels between globalization and terrorism that we can see their interconnectedness, which terrorism has exploited.

The patterns described here provide a general overview. We encourage readers to explore the Global Terrorism DatabaseTM and consider contextual information for a comprehensive assessment. We have presented the data of terrorist attacks in the world for nearly 50 years. In 2014 terrorist violence peaked, in 2014 nearly 17,000 attacks and more than 44,000 total deaths have 
happened worldwide from terrorist attacks and violence.

In the following models, we have given descriptions of terrorist attacks around the world over about 50 years worldwide. We have also presented the number of victims, deaths from violence, and terrorist attacks over nearly 50 years worldwide (Figure 1).

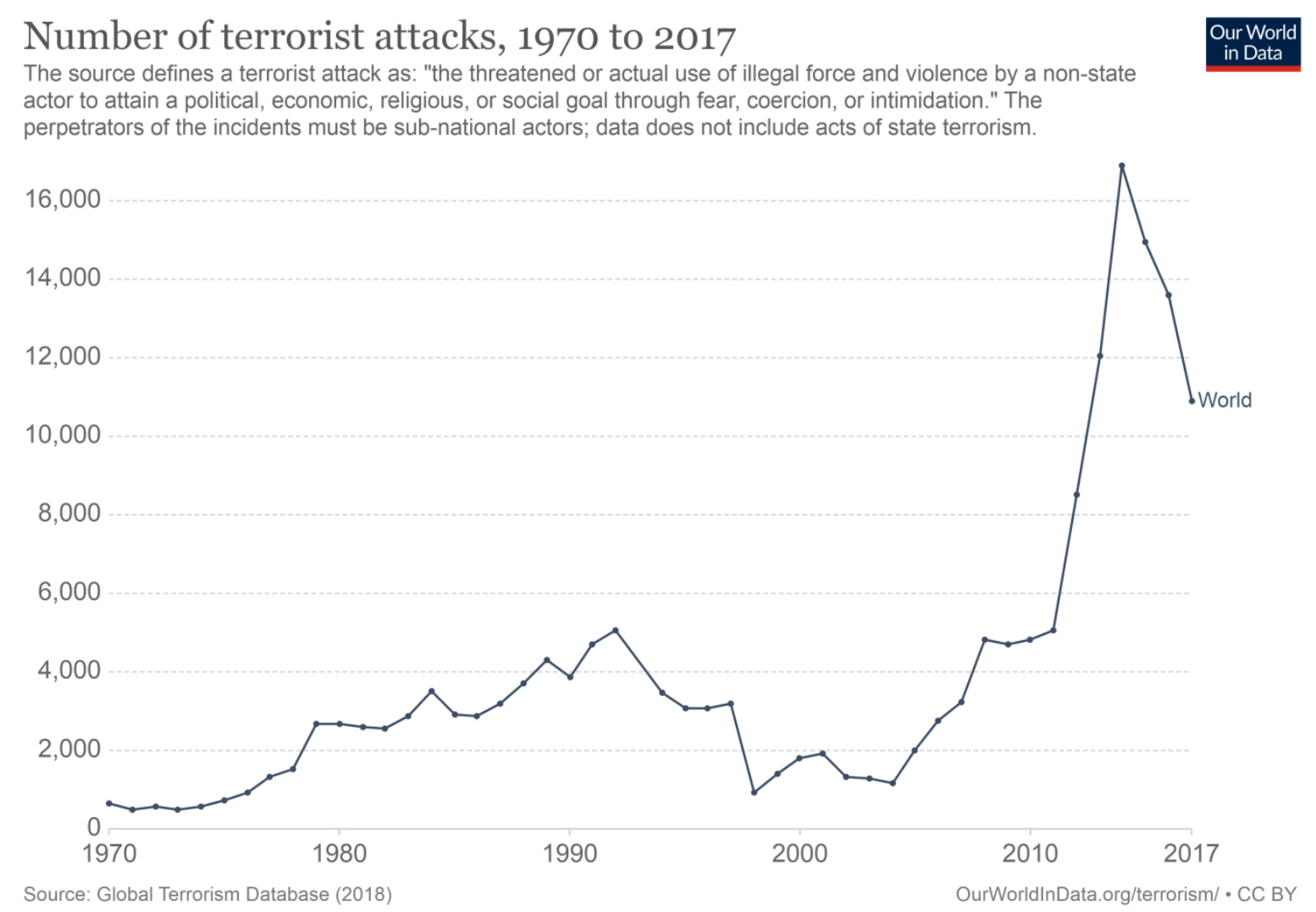

Figure $1[5]$

In the above model, we have presented the number of terrorist attacks during the period 19702017, which clearly shows that the largest attacks occurred in 2014. After 2001, terrorist attacks in the world have only continued to increase by raising the number curve of terrorist attacks around the globe. If we analyze the curve shown above, it is clear that by 2014 terrorism reached its peak of attacks in the last 50 years or so. There are various reasons for these attacks which extend to many levels, but within these areas lies the level and the economic impact, as well as the development of globalization, which facilitated terrorists to carry out these attacks during these different periods around the world.

These attacks of the various terrorist groups presented in the model above through the curve include any damages that have occurred to victims, people, as well as economic damage in the various states where the attacks took place.
In the following model, we will present the number of deaths from terrorist attacks in the world for about 50 years (Figure 2).

From the above presentation for the number of deaths from terrorist attacks in the world the curve clearly shows that in 2014 from terrorist attacks there are the most deaths, the number exceeded more than 44,000 total deaths. If you look at 2013, the number of deaths from terrorist attacks was more than 22,000 , then within a year, this number of deaths doubled, making 2014 the most horrible year of deaths caused by terrorism in about 50 last years.

Terrorism over the years has been constantly moving, rising, and falling but in general, has always been active in attacking the targets and interests that it has targeted. This is the purpose of terrorism to act in a multifaceted, comprehensively and in various forms and ways, to incite violence and fear on a large scale. 
Number of deaths from terrorist attacks, World, 1970 to 2017

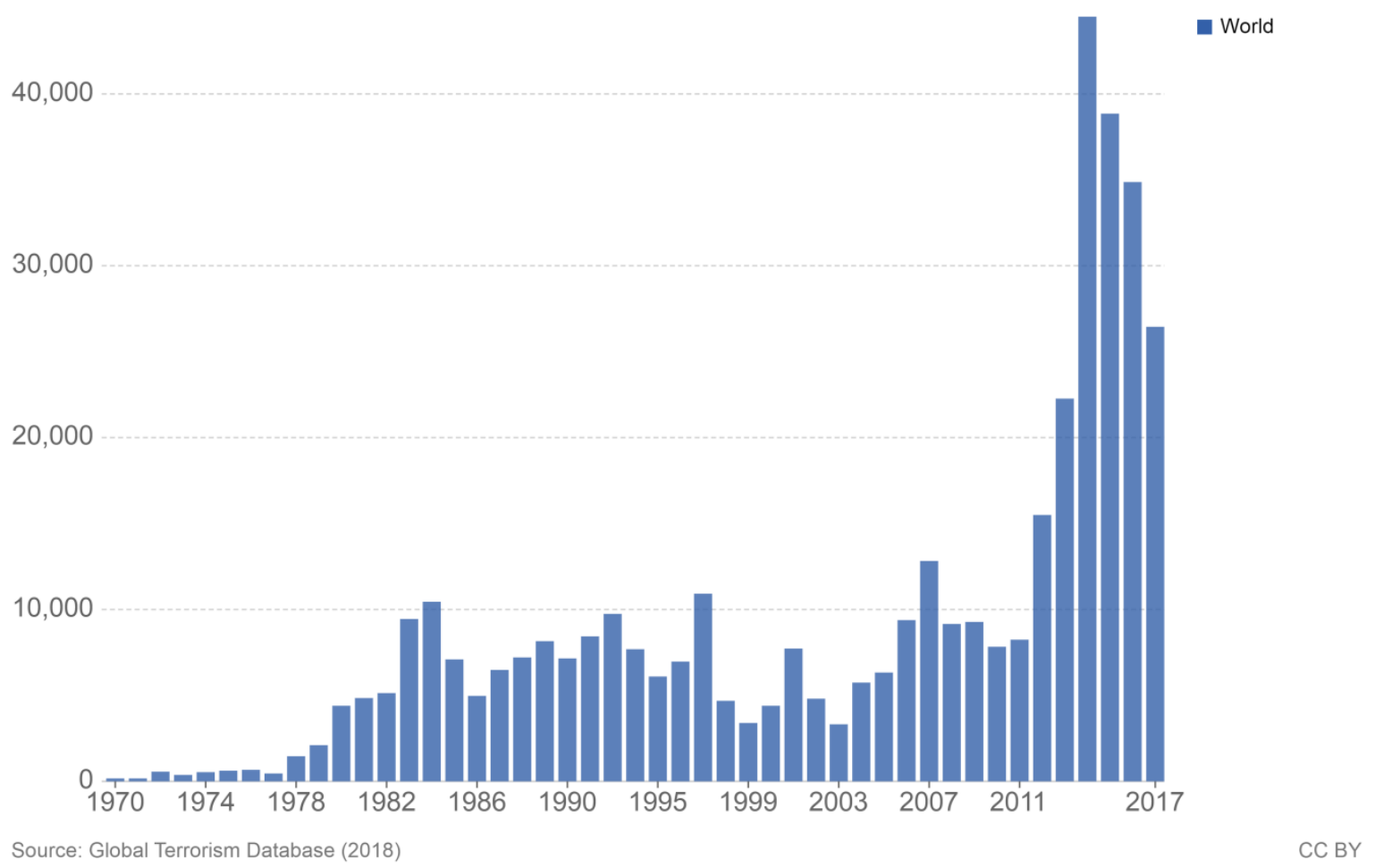

Figure 2 [5]

Globalization and the development of the impact of globalization in certain periods have been exploited by terrorism as well as in a comprehensive and not a treatable way, which has often caused confusion and panic even in developed countries and with great certainty.
During the last period, terrorism has started to have a decrease in their activities. If we analyze recent years, we see that terrorist attacks and the victims of these attacks are increasingly declining (Figure 3).

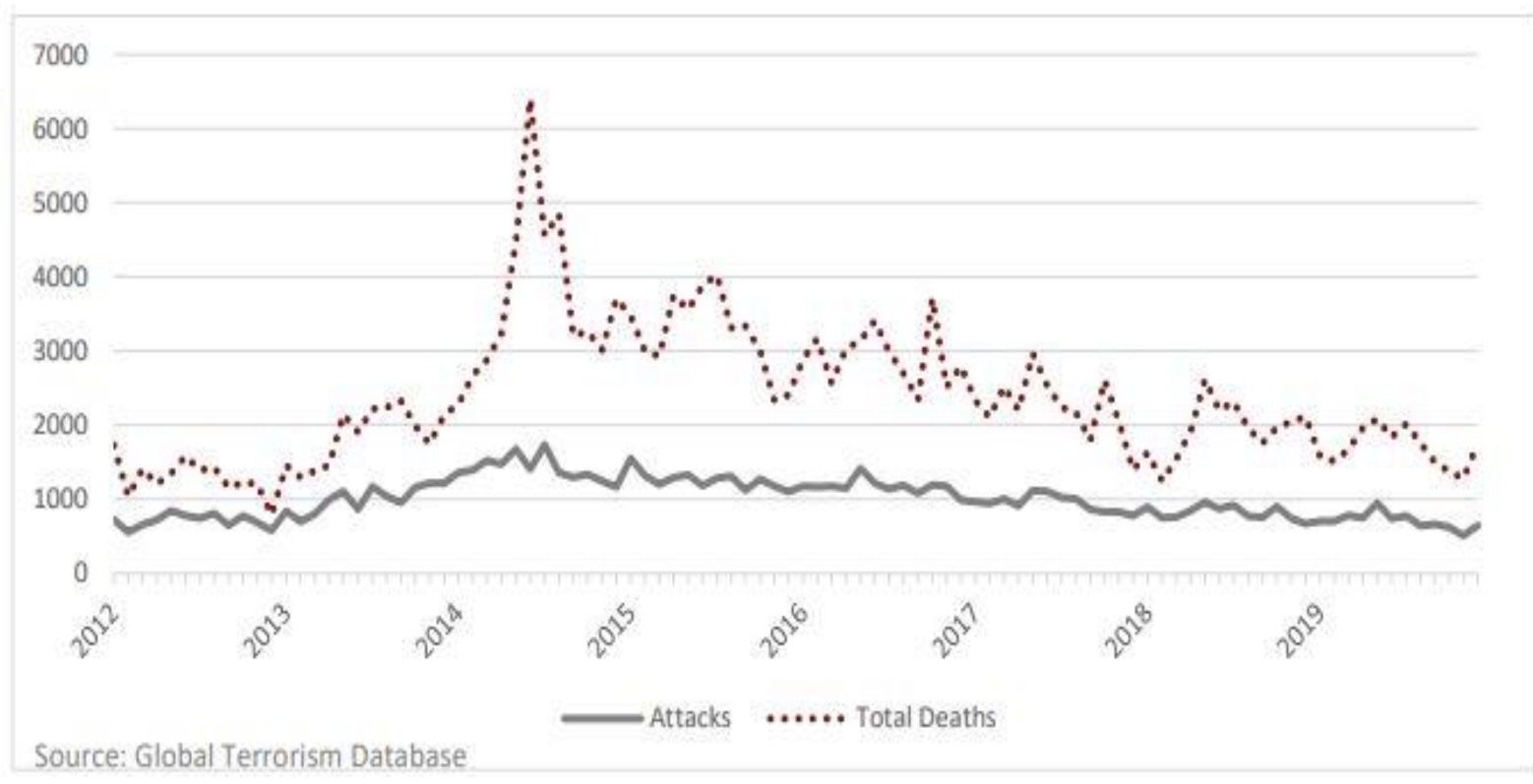

Figure 3 - Terrorist attacks and total deaths worldwide, 2012-2019 [5] 
Based on the above presentation we can see that from the period 2014 to 2019 global terrorism in these last 5 years has suffered a great decline. After terrorist violence peaked in 2014 at nearly 17,000 attacks and more than 44,000 total deaths. The total number of terrorist attacks worldwide dropped by $50 \%$ between 2014 and 2019, and the total number of deaths dropped by 54\%. Regional and global trends have changed significantly over the years. The models described here, taken from the Global Terrorism Database, provide a general overview.
Globalization can be said to have made even greater the economic impact of terrorism. Terrorism has cost the world in general over the years. Below we will present the trends of the economic impact of terrorism globally from 2000 to 2018.

The period we have presented includes a coherence during which the cost of terrorism has changed from time to time, which has changed and fallen over the years, as can be seen in our presentation (Figure 4).

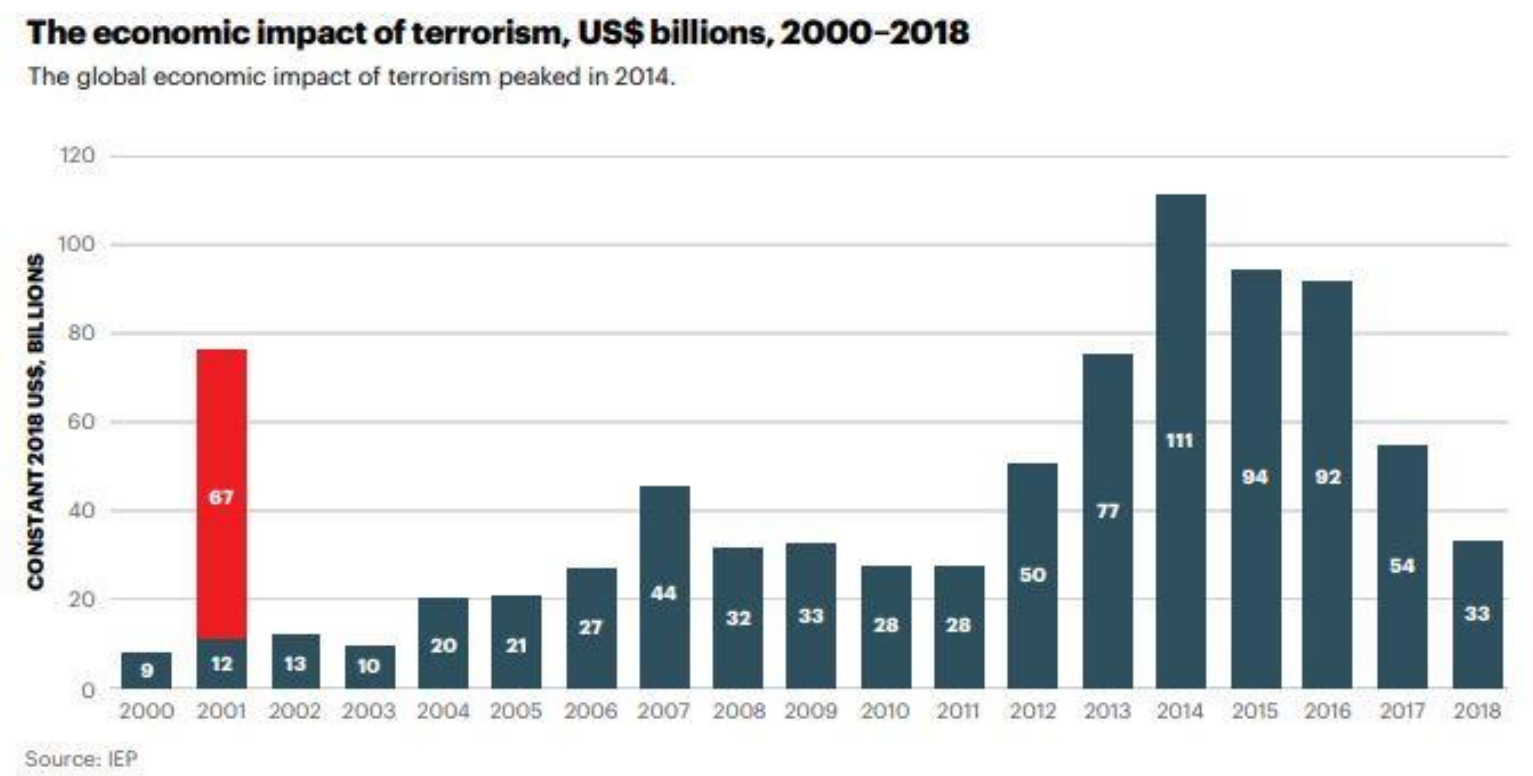

Figure 4 - The economic impact of terrorism, 2000-2018 [5]

The economic impact of terrorism peaked in 2014, when, as shown in the curve, it reached a cost of $\$ 111$ billion. This culmination goes beyond the terrorist attacks of 11 September 2001.

Every year global terrorism costs the world a very high overall cost. These economic impacts of terrorism include costs from many categories such as; deaths, injuries, destruction of property, various shopping centers, etc.

In the above presentation, it is clear that from 2014 to 2018 the economic impact of terrorism has decreased significantly, which gives a positive trend. In 2018 the global economic impact of terrorism reached the US $\$ 33$ billion, a 38\% drop from its 2017 level, as well as a very deep decline from 2014.

The reduction in the economic impact of terrorism reflects the decreasing level of violence from global terrorism. The improvement over the last four years is largely driven by the declining level of terrorism-related violence in Iraq, Nigeria, and Pakistan. Since 2014, the economic impact of terrorism has declined by 62 percent in Nigeria, 82 percent in Iraq, and 90 percent in Pakistan (Institute for Economics \& Peace, 2019).

All our presentations based on figures and percentages which are derived from certain databases represent a clear understanding of the impact of terrorism worldwide and its rise. Certain years and developments over the years have contributed to the escalation of terrorist attacks around the world in various countries. The trends that we can see for the decline of terrorist attacks in recent years are based on facts and statistics in general, which can be influenced by many developments and changes at the global level.

The rise of terrorism in direct and indirect forms has been helped and preceded by the development of globalization. the capitalism of the world and the changes in trends around the world directly affect the changes of terrorism, taking 
various forms and developments which depend on the need and time.

Globalization is increasingly expanding and developing across the globe, the world is increasingly facing different trends as well as different confrontations, terrorism and its impact in all spheres is also a problem with which the world continues to face in the future. The trend of terrorism is intertwined with the development and advancement of globalization, which directly affects the world and its stability and that of countries in particular.

\section{CONCLUSIONS}

The rise and spread of globalization at a great speed give impossible tendencies to predict the security and future of the world in general. The great changes that are taking place in the world have to do with the implication of globalization and its processes which extend and affect many areas.

The development of new technologies and their advancement, in general, has made possible great facilitation. Most of the facilitations brought are used and misused by different individuals and groups for a variety of purposes.

It can be said that globalization has changed the world in which we live, but at the same time has brought new challenges and confrontations for the world at large. Globalization gave impetus and facilitation to the rise of terrorism. Terrorism also changed its approach and tactics, advancing more and more thanks to the developments brought about by globalization.

For the last 50 years or so in the development of the world as a whole, the spread and rise of terrorism across the globe can be seen, which is precisely what happened as a result of the relief that globalization has brought. The opening of borders, the cooperation of markets, corporations, and many other actors and factors brought about by globalization, has led to the rise and development of global terrorism.

Terrorist groups benefit from the development of technology and the spread of globalization. This is a danger and a confrontation for the whole world. Terrorism is influenced and developed by many factors, external and internal, but which are always difficult to identify and prevent

The world as a whole is facing the threat of terrorism. Terrorism is a global war that has no address or representation. Terrorism is used for different purposes and interests, with different port cohesions that affect the whole world in general.

The fight against terrorism has always been and remains a key problem for the entire globe. Cooperation and coordination between countries to combat this phenomenon have often been not very successful. Terrorism coherent with the development and spread of globalization is using vacuums to realize its interests.

It can be said that based on past experiences and concrete cases, globalization has facilitated and increased terrorism.

\section{REFERENCES}

1. Giddens, A. (1990). The Consequences of Modernity. Cambridge: Polity Press.

2. Goodman, S. E., Kirk, J. C., \& Kirk, M. H. (2007). Cyberspace as a medium for terrorists. Technological Forecasting and Social Change, 74(2), 193-210. doi: 10.1016/j.techfore.2006.07.007

3. Held, D., McGrew, A., Goldblatt, D., \& Perraton, J. (1999). Global Transformations: Politics, Economics, Culture. Cambridge: Policy Press.

4. Helton A, Z. D. (2002). Globalization, Terror, and the Movements of People. The International lawyer, 36(1), 91-101.

5. Institute for Economics and Pease. (2019). Global Terrorism Index 2019: Measuring the Impact of

Terrorism. Retrieved from http://visionofhumanity.org/app/uploads/2019/11/GTI2019web.pdf

6. Kirshner, J. (2013). Globalization and National Security. New York: Routledge.

7. Margalit., Y. (2012). Lost in Globalization: International Economic Integration and the Sources of Popular Discontent. International Studies Quarterly, 56(3), 484-500. 
8. Mekaj, M. G., \& Aliaj, M. K. (2018). Globalisation as a facilitator of terrorism. ILIRIA International Review, 8(1). doi: 10.21113/iir.v8i1.400

9. Merson, M. (2005). Global Health: Diseases, Programs, Systems, and Policies (2nd ed.). New York: Jones \& Bartlett.

10. Murphy, J. (2002). The Impact of Terrorism on Globalization and ViceVersa. The International Lawyer, 36(1), 77-89.

11. Ravenhill, J. (2017). Global Political Economy (5th ed.). Oxford: Oxford University Press.

12. Richardson, L. (2006). The roots of terrorism. New York: Routledge.

13. Zimmermann, E. (2011). Globalization and terrorism. European Journal of Political Economy, 27, S152-S161. doi: 10.1016/j.ejpoleco.2011.09.003 